\title{
Defining Thermophysical Parameters of Electric Devices Based on Solution of Inverse Heat Transfer Problem
}

\author{
Yuriy Alekseevich Bachvalov ${ }^{1}$, Nikolai Ivanovich Gorbatenko ${ }^{1} \&$ Valeriy Viktorovich Grechikhin ${ }^{1}$ \\ ${ }^{1}$ Platov South-Russian State Polytechnic University (NPI), Russia \\ Correspondence: Valeriy Viktorovich Grechikhin, Platov South-Russian State Polytechnic University (NPI), \\ 346428, Novotcherkassk, Prosveshenija, 132, Russia.
}

Received: December 18, 2014

Accepted: January 2, 2015

Online Published: July 30, 2015

doi:10.5539/mas.v9n8p386

URL: http://dx.doi.org/10.5539/mas.v9n8p386

\begin{abstract}
This paper describes application of the study methods based on the solution of inverse problems of mathematical physics to define thermophysical parameters of electric devices. The mathematical model of the device is developed based on equations of non-stationary heat conductivity. The algorithm to define thermohysical parameters is developed; this algorithm uses the finite element method to solve a direct heat transfer problem and the gradient method to minimize the objective function. Examples of the algorithm application are given. The problem to define an equivalent heat transfer coefficient of the solenoid area covered with heavy winding and a heat emission from its inside surface is considered. In the second example thermophysical parameters of electromagnetic valve actuator of an ICE (internal combustion engine) gas distribution mechanism are defined. The obtained results show that thermophysical parameters and temperature distribution in non-stationary and steady-state operating conditions of electrical devices may be evaluated with adequate efficiency based on the solution of inverse heat transfer problems.
\end{abstract}

Keywords: inverse problems, heat transfer, non-stationary heat conductivity, electrical device

\section{Introduction}

The need to save energy and resources leads to creation of technical units characterized by marginal operation, high thermal, electro-magnetic and mechanical loads on their materials and structures. All of these require a reliable identification of the study subjects i.e. parameters and characteristics of materials and structures used in mathematical modeling shall be defined with an adequate accuracy. At the same time some of the parameters and characteristics can not be directly defined. In such cases the only way to obtain necessary information is to use a study approach based on solving inverse problems of mathematical physics (Alifanov, 1994), (Bachvalov et al., 2013), (Beck et al., 1985), (Bui, 1994), (Grechikhin and Grecova, 2011), (Korovkin et al., 2006), (Ozisik and Orlande, 2000), (Tikhonov and Arsenin, 1977), (Vatulyan, 2007). It is one of the main trends in studying physical processes and optimizing operating parameters of technical units and operating procedures.

Functioning of a number of technical units, including electric devices, is accompanied with heat transfer processes, which in their turn have an impact on the unit technical characteristics. Tougher tolerances are being established for temperature ranges of parts and devices, requirements to reliability in maintaining these ranges and reduction of material intensity of structures are getting tougher. Therefore thermophysical study of electric devices and calculation of their thermal rates becomes very important. Effectiveness of decisions made depends a lot on completeness and accuracy of heat transfer study. This justifies a necessity to conduct full-scale and modeling tests of devices (Grechikhin and Grecova, 2011). During the tests temperature $T_{*}\left(M_{i}, t\right)$ is measured in points $M_{i}$ of the device on a bounded time interval $\left[0, t_{e}\right]$. Then, a thermal mathematical model of the device is adjusted by variation of a system of $n$ thermophysical parameters $x_{1}, x_{2}, \ldots, x_{p}$ in such a way, that the values $T_{*}\left(M_{i}, t\right)$ of the device agree with $T\left(M_{i}, t\right)$ of the model on the interval $\left[0, t_{e}\right]$ with an adequate accuracy. Then, using the model, desired time to achieve the steady-state condition $t_{s}$ and temperature distribution of the device in this condition are defined.

Heat transfer and heat conductivity coefficients which values either unknown or known but with low accuracy can be used as adjustable thermophysical parameters. It is known, that temperature measurement data remain the main source of inaccuracy in solving applied problems to define these parameters (Beck et al., 1985). This is caused by performance features of temperature sensors. Therefore it is practical to identify heat transfer and heat 
conductivity coefficients based on the solution of inverse heat transfer problems (Alifanov, 1994), (Beck et al., 1985), (Ozisik and Orlande, 2000). This paper describes a mathematical model and an algorithm to define thermophysical parameters of electric devices using such an approach.

Two problems are solved. The first one determines an equivalent heat transfer coefficient for a solenoid heavy winding of a measuring system designed to define magnetization curves (B-H curves) and hysteresis loops for ferromagnetic materials as well as a heat transfer coefficient between the solenoid inside surface and the ambient air. The second problem defines thermophysical parameters of an electromagnetic valve actuator in an ICE gas distribution mechanism.

This paper shows the results of using thermal testing methods for the stated devices based on the solution of an inverse heat transfer problem resulting in essential decrease of testing time and power consumption.

\section{Methodology}

\subsection{Statement of the Problem}

The studied electric device together with the ambient environment are represented as a multiply connected domain $V$ (Fig. 1), with subdomains $V_{i}$, and heat sources with volume density $q_{v}$.

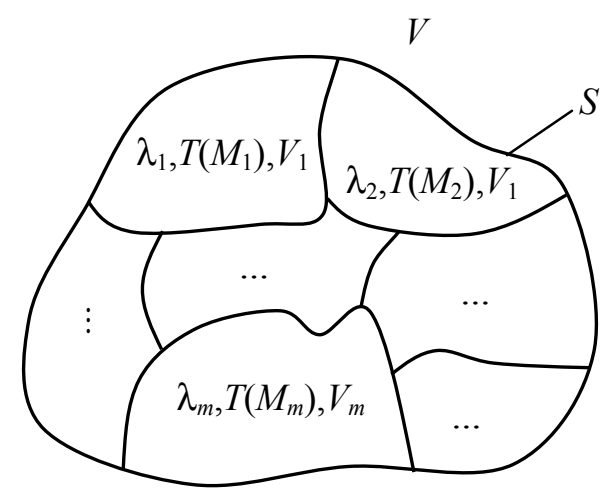

Figure 1. Multiply connected domain

Non-stationary temperature distribution in the domain $V$ is described with a system of equations

$$
\rho_{i} c_{i} \frac{\partial T_{i}\left(M_{i}\right)}{\partial t}=\operatorname{div}\left(\lambda_{i} \operatorname{grad} T_{i}\left(M_{i}\right)\right)+q_{v_{i}} ; i=1,2, \ldots, m,
$$

where $T\left(M_{i}\right)$ - temperature in the point $M_{i} \in V_{i} ; \lambda_{i}-$ heat transfer coefficient of the medium in $V_{i} ; q_{v_{i}}-$ volume density of the heat sources in a subdomain $V_{i} ; \rho_{i}-$ density of the medium in $V_{i} ; c_{i}-$ specific heat capacity of the medium in $V_{i} ; m$ - number of bodies in the studied domain $V$.

Boundary conditions are added to the system of equations (1):

$$
\begin{gathered}
\lambda \frac{\partial T}{\partial n}=-\alpha\left(T-T_{\mathrm{amb}}\right) \text { on } S \\
T\left(M_{i}\right)=T\left(M_{i+1}\right), \lambda_{i} \frac{\partial T}{\partial n}\left(M_{i}\right)=\lambda_{i+1} \frac{\partial T}{\partial n}\left(M_{i+1}\right)
\end{gathered}
$$

at interfaces of media with different $\lambda_{i}$. Here, $\alpha$ - heat emission coefficient, $T_{\mathrm{amb}}-$ ambient temperature.

Initial temperature distribution in the domain $V$ at a point of time $t=0$ is considered to be known:

$$
T\left(M_{i}, 0\right)=T\left(M_{i}\right), i=1,2, \ldots, m .
$$

Problem (1) - (4) describes heat transfer in linear and non-linear media. (1) - (4) forms a direct problem to find the function $T\left(M_{i}, t\right)$. Analytical (Polyanin et al., 2005) and numerical (Samarskii, 2001), (Zienkiewicz and Taylor, 2000) methods of solving this direct heat transfer problem are well known.

Let us consider an inverse problem where, for instance, in addition to $T\left(M_{i}, t\right)$, a heat transfer coefficient $\lambda(T)$ and a heat emission coefficient $\alpha(T)$ are unknown. The unknown coefficients shall be restored by solving the system (1) with conditions (2) - (4) and additional information 


$$
T_{*}\left(M^{*}, t\right)=\widetilde{T}_{M}(t), T_{*}\left(N^{*}, t\right)=\widetilde{T}_{N}(t), M^{*}, N^{*} \in V, t \in\left[0, t_{\mathrm{u}}\right] .
$$

where $M^{*}, N^{*}$ - fixed points, where temperature is measured with an error $\Delta T_{*}$.

The formed problem belongs to inverse heat transfer problems of a mixed type (coefficient and boundary). The studies (Alifanov et al., 1995), (Borukhov et al., 2005) prove the existence and uniqueness of the solutions to such problems. Solution stability is ensured by selecting them in a class of functions with a bounded norm (Tikhonov's stability) (Tikhonov and Arsenin, 1977).

\subsection{Computational Algorithm}

To define thermophysical parameters of electric devices based on the solution of an inverse heat transfer problem we shall use a conjugate gradient method (Alifanov et al., 1995), (Dinh and Reinhardt, 1998), (Rumyantsev, 1985). It is an iterative process of minimizing the objective function

$$
J(\lambda, \alpha)=\int_{0}^{t_{\mu}}\left[T\left(N^{*}, t\right)-T_{*}\left(N^{*}, t\right)\right]^{2} d t+\int_{0}^{t_{\mu}}\left[T\left(M^{*}, t\right)-T_{*}\left(M^{*}, t\right)\right]^{2} d t .
$$

Iterations, which define minimizing sequence of the function (5), are imposed with recursion

$$
\begin{gathered}
\lambda^{(n+1)}=\lambda^{(n)}-\rho \frac{\partial J^{(n)}}{\partial \lambda}, n=1,2, \ldots ; \\
\alpha^{(n+1)}=\alpha^{(n)}-\rho \frac{\partial J^{(n)}}{\partial \alpha}, n=1,2, \ldots,
\end{gathered}
$$

where $\lambda^{(n)}, \lambda^{(n+1)}-n$ and $(n+1)$ approximation for $\lambda(T) ; \alpha^{(n)}, \alpha^{(n+1)}-n$ and $(n+1)$ approximation for $\alpha(T) ; \frac{\partial J^{(n)}}{\partial \lambda}, \frac{\partial J^{(n)}}{\partial \alpha}-$ partial derivatives of the function (6).

The iterative process is terminated when the equation

$$
\int_{0}^{t_{u}}\left[T^{(n)}\left(N^{*}, t\right)-T_{*}\left(N^{*}, t\right)\right]^{2} d t+\int_{0}^{t_{u}}\left[T^{(n)}\left(M^{*}, t\right)-T_{*}\left(M^{*}, t\right)\right]^{2} d t \leq \varepsilon \Delta T_{*}
$$

is true,

where $\varepsilon$ - given empirical parameter, defined using the criteria described in (Samarskii, 2001), (Tikhonov et al., 1995), $T^{(n)}\left(N^{*}, t\right), T^{(n)}\left(M^{*}, t\right)$ - problem solution (2) - (4) when $\lambda(T)=\lambda^{(n)}(T)$ and $\alpha(T)=\alpha^{(n)}(T)$.

Considering (6) - (9) we shall present the sequence for solving the inverse problem (2) - (5). We shall select initial approximation $\lambda(T)=\lambda^{(0)}(T), \alpha(T)=\alpha^{(0)}(T)$ and increments $\Delta \lambda, \Delta \alpha, \rho$ and $\Delta t$.

Iteration loop of the algorithm for each $n=0,1,2, \ldots$ consists of the steps as follows:

1. We solve a direct problem (2) - (4) where $\lambda(T)=\lambda^{(n)}(T), \alpha(T)=\alpha^{(n)}(T)$ and define a temperature field including the values $T\left(N^{*}, t_{j}\right)$ and $T\left(M^{*}, t_{j}\right), j=1,2, \ldots, n$, at the time points $t_{j}$.

2. We find a value of the function (6).

3. We check the condition for termination of the calculations (9). If the condition (9) is satisfied, values $\lambda(T)=\lambda^{(n)}(T), \alpha(T)=\alpha^{(n)}(T)$ and $T^{(n)}\left(N^{*}, t\right), T^{(n)}\left(M^{*}, t\right)$ are considered to be the solution of the problem. If the condition (4) is not satisfied, then go to 4 . 
4. We find the next values of the desired variables using a gradient method and the equations (7) and (8).

\section{Go back to 1 .}

As a rule numerical implementation of this algorithm is based on the application of a finite element method (FEM) or a finite difference method.

\section{Results and Discussion}

\subsection{Thermophysical Parameters of the Measuring System Solenoid}

The applicable standards (IEC Standard 60404) for measuring static magnetic characteristics of soft magnetic materials are not adopted for testing under changing temperature and mechanical stresses. For instance, during operation the temperature of automobile starters and generators may reach $200{ }^{\circ} \mathrm{C}$, their stress $-200 \mathrm{MPa}$. In cases like that it is practical to take measurements on an open magnetic circuit, using a solenoid to magnetize the material (Hall et al., 2009).

Let us consider a problem of finding thermophysical parameters of a solenoid of a measuring system designed to define magnetization curves (B-H curves) and hysteresis loops for soft magnetic materials. They include an equivalent heat transfer coefficient $\lambda_{2}$ of area 2 of the solenoid, covered with heavy winding, and a heat emission coefficient $\alpha_{1}$ between the solenoid inside surface with a radius $r_{1}$ and the ambient air (Fig. 2).

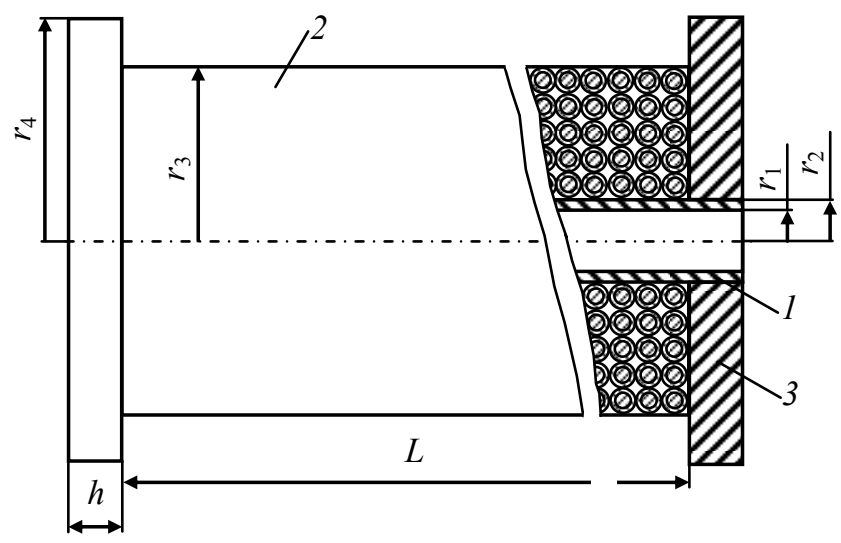

Figure 1. Sketch of a solenoid

Smallness of the radius $r_{1}$ makes it harder to measure thermophysical parameters inside the solenoid and allows for only one temperature sensor to be placed inside that area.

Considering axial symmetry of the solenoid, we will use a cylindrical coordinate system $r 0 z$.

In this case a system of equations (1) is

$$
\rho_{i} c_{i} \frac{\partial T_{i}}{\partial t}=\frac{1}{r} \frac{\partial}{\partial r}\left(\lambda_{i} r \frac{\partial T_{i}}{\partial r}\right)+\frac{\partial}{\partial z}\left(\lambda_{i} \frac{\partial T_{i}}{\partial z}\right)+q_{V_{i}}, i=1,2, \ldots, m
$$

The initial temperature distribution in the solenoid at the point of time $t=0 \quad T\left(N_{i}, 0\right)=T\left(N_{i}\right), i=1,2,3$; and the ambient temperature $T_{\text {amb }}$ are considered to be known.

Boundary conditions are:

- On the inside surface of solenoid area 1

$$
\left.\lambda_{1} \frac{\partial T_{1}}{\partial n}\right|_{r=r_{1}}=-\alpha_{1}\left[T_{1}\left(r_{1}, t\right)-T_{\mathrm{amb}}\right] ;
$$

- $\quad$ On the outside surface of solenoid area 2

$$
\left.\lambda_{2} \frac{\partial T_{2}}{\partial n}\right|_{r=r_{3}}=-\alpha_{2}\left[T_{2}\left(r_{3}, t\right)-T_{\mathrm{amb}}\right] ;
$$


- On the surfaces of area 3, which are in contact with the ambient environment:

- At the media interfaces

$$
\frac{\partial T_{3}}{\partial n}=0 ;
$$

when $r=r_{2}$

- at the interfaces of areas 1 and 3

$$
T_{1}\left(r_{2}, t\right)=T_{2}\left(r_{2}, t\right) ;\left.\quad \lambda_{1} \frac{\partial T_{1}}{\partial n}\right|_{r=r_{2}}=\left.\lambda_{2} \frac{\partial T_{2}}{\partial n}\right|_{r=r_{2}} ;
$$

$$
T_{1}(N, t)=T_{3}(N, t) ; \quad \lambda_{1} \frac{\partial T_{1}}{\partial n}=\lambda_{3} \frac{\partial T_{3}}{\partial n}
$$

- at the interfaces of areas 2 and 3

$$
T_{2}(N, t)=T_{3}(N, t) ; \lambda_{2} \frac{\partial T_{2}}{\partial n}=\lambda_{3} \frac{\partial T_{3}}{\partial n},
$$

where $\alpha_{1}, \alpha_{2}$ - heat emission coefficients between the inside and outside surfaces of the solenoid and the ambient air, respectively.

Computational domain is given in Fig. 3 .

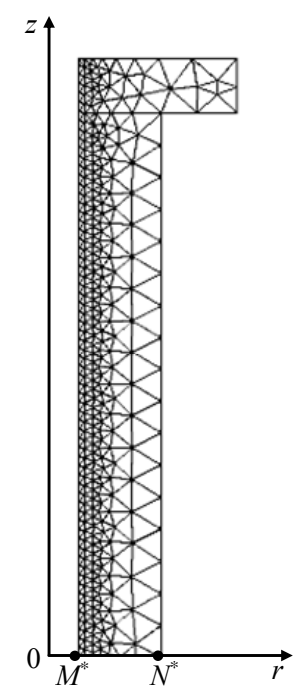

Figure 3. Computational domain with FEM mesh (709 elements)

$M^{*}, N^{*}$ - points where temperature sensors are placed

Unknown values are $\lambda_{2}, \alpha_{1}$ and $T_{i}=T\left(N_{i}, t\right), i=1,2,3$.

We shall formulate a problem: it is required to define the equivalent heat transfer coefficient $\lambda_{2}$ of the area covered with the solenoid winding, the heat emission coefficient $\alpha_{1}$ and the functions $T_{i}=T\left(N_{i}, t\right), i=1,2,3$, which satisfy the system of equations (10) and the above given initial and boundary conditions; there are additional known data- functions $T_{*}\left(N^{*}, t\right)$ and $T_{*}\left(M^{*}, t\right)$, obtained by taking measurements in $N^{*}$ and $M^{*}$

(Fig. 3) with error $\Delta T_{*}$ on the time interval $\left[0, t_{e}\right]$.

Let us convert the solution of this problem to the solution of a sequence of direct problems - a system of equations (10) with the above given initial and boundary conditions using the FEM.

We shall select initial approximation $\lambda_{2}^{(0)}, \alpha_{1}^{(0)}$ and increments $\Delta \lambda_{2}, \Delta \alpha_{1}, \rho_{1}, \rho_{2}$ and $\Delta t$. 
Then, according to the algorithm, we shall solve a direct problem using the FEM when $\lambda_{2}=\lambda_{2}^{(n)}, \alpha_{1}=\alpha_{1}^{(n)}$ and define the temperature field, including $T\left(N^{*}, t_{j}\right)$ and $T\left(M^{*}, t_{j}\right), j=1,2, \ldots, n$, at the points of time $t_{j}$.

As in our case the functions $T_{\text {и }}\left(N^{*}, t\right)$ and $T_{\text {и }}\left(M^{*}, t\right)$ are represented as table data, instead of (6) we will use a function type

$$
J^{(n)}\left(\lambda_{2}^{(n)}, \alpha_{1}^{(n)}\right)=\beta_{1} \sum_{j=1}^{p}\left[T\left(N^{*}, t_{j}\right)-T_{*}\left(N^{*}, t_{j}\right)\right]^{2}+\beta_{2} \sum_{j=1}^{p}\left[T\left(M^{*}, t_{j}\right)-T_{*}\left(M^{*}, t_{j}\right)\right]^{2},
$$

where $p$ - number of temperature measurements on the interval $\left[0, t_{e}\right] ; \beta_{1}, \beta_{2}$ - weight factors, $\beta_{1}=1 / 3$; $\beta_{2}=2 / 3$.

According to (9), we shall check the condition for calculation termination. If the condition (9) is not satisfied we start calculating, similar to (7) and (8), the next values of the desired variables:

$$
\begin{aligned}
& \lambda_{2}^{(n+1)}=\lambda_{2}^{(n)}-\rho_{2} \frac{\partial J^{(n)}}{\partial \lambda_{2}} ; \\
& \alpha_{1}^{(n+1)}=\alpha_{1}^{(n)}-\rho_{1} \frac{\partial J^{(n)}}{\partial \alpha_{1}},
\end{aligned}
$$

and solve the direct problem again using the FEM when $\lambda_{2}=\lambda_{2}^{(n+1)}, \alpha_{1}=\alpha_{1}^{(n+1)}$.

Let us consider using the algorithm to define the heat emission coefficient $\alpha_{1}$ and the equivalent heat transfer coefficient $\lambda_{2}$ of the solenoid area, covered with heavy winding of a copper wire with the following parameters: $r_{1}=12 \cdot 10^{-3} \mathrm{~m} ; \quad r_{2}=15 \cdot 10^{-3} \mathrm{~m} ; \quad r_{3}=50 \cdot 10^{-3} \mathrm{~m} ; \quad r_{4}=85 \cdot 10^{-3} \mathrm{~m} ; \quad h=25 \cdot 10^{-3} \mathrm{~m} ; \quad L=505 \cdot 10^{-3} \mathrm{~m} ;$ $\lambda_{1}=\lambda_{3}=0.3 \mathrm{~W} /(\mathrm{m} \cdot \mathrm{K})$ (material - textolite); specific heat capacity of $\operatorname{copper} c_{C u}=385 \mathrm{~J} /(\mathrm{kg} \cdot \mathrm{K})$; density of copper $\rho_{C u}=8.9 \cdot 10^{3} \mathrm{~kg} / \mathrm{m}^{3}$; number of turns $w=2514$; wire diameter (copper only) $2.1 \cdot 10^{-3} \mathrm{~m}$; insulation thickness $0.2 \cdot 10^{-3} \mathrm{~m}$; volume of copper $V_{C u}=1.02 \cdot 10^{-3} \mathrm{~m}^{3}$; we shall consider that specific heat capacity and density values of other materials equal to zero; test time $t_{e}=30 \mathrm{~min}$.

Table 1 gives measurements of the temperature $T_{*}\left(N^{*}, t\right)$ and $T_{*}\left(M^{*}, t\right)$ in the points $N^{*}$ and $M^{*}$, the heat flux density $q_{*}$, from the surface of area 2, the ambient temperature $T_{\text {amb }}$ measured with ITP-MG4.03/3(1) Potok heat flux density and temperature measuring device with the solenoid winding powered from d.c. power source with voltage $U=18.75 \mathrm{~V}$, current $I=7.53$ A. The instrument error: $\pm 6 \%$ relative error for heat flux density, and $\pm 0.2{ }^{\circ} \mathrm{C}$ absolute error for temperature.

Table 1. Experimental data

\begin{tabular}{cccccccc}
\hline$t, \min$ & 0 & 5 & 10 & 15 & 20 & 25 & 30 \\
\hline$T_{*}\left(N^{*}, t\right),{ }^{\circ} \mathrm{C}$ & 22 & 25.5 & 29.2 & 32.0 & 34.6 & 37.7 & 40.1 \\
$T_{*}\left(M^{*}, t\right),{ }^{\circ} \mathrm{C}$ & 22 & 24.5 & 29.3 & 33.8 & 38.6 & 43.2 & 47.8 \\
$q_{*}, \mathrm{~W} / \mathrm{m}^{2}$ & 0 & 43.1 & 77.2 & 106.1 & 137.1 & 165.6 & 188.7 \\
\hline
\end{tabular}




\begin{tabular}{llllllll}
$T_{\text {amb }},{ }^{\circ} \mathrm{C}$ & 22 & 22 & 22 & 22 & 22 & 22 & 22 \\
\hline
\end{tabular}

Using data from Table 1, we shall define the mean value of the heat emission coefficient from the solenoid surface

$$
\alpha_{2}=\frac{q_{*}}{T_{*}\left(N^{*}, t\right)-T_{\text {amb }}}=11,1 \quad \mathrm{~W} /\left(\mathrm{m}^{2} \cdot \mathrm{K}\right)
$$

Now we shall find other solenoid parameters, reduced to the volume of area 2 (solenoid winding) $V_{2}$ :

$$
\begin{gathered}
V_{2}=\pi\left(r_{3}^{2}-r_{2}^{2}\right) L=3,1416\left[\left(50 \cdot 10^{-3}\right)^{2}-\left(15 \cdot 10^{-3}\right)^{2}\right] \cdot 505 \cdot 10^{-3}=3.61 \cdot 10^{-3} \mathrm{~m}^{3} ; \\
q_{V_{2}}=\frac{U I}{V_{2}}=\frac{18.75 \cdot 7.53}{3.61 \cdot 10^{-3}}=39122 \mathrm{~W} / \mathrm{m}^{3} ; \\
\rho_{2} c_{2}=\rho_{C u} c_{C u} \frac{V_{C u}}{V_{2}}=8.9 \cdot 10^{3} \cdot 385 \cdot \frac{1.02 \cdot 10^{-3}}{3.61 \cdot 10^{-3}}=1.64 \cdot 10^{6} \quad \mathrm{~J} /(\mathrm{kg} \cdot \mathrm{K}) .
\end{gathered}
$$

We consider that $\quad \lambda_{2}^{(0)}=0.01 \quad \mathrm{~W} /(\mathrm{m} \cdot \mathrm{K}), \quad \Delta \lambda=0.003 \quad \mathrm{~W} /(\mathrm{m} \cdot \mathrm{K}), \quad \varepsilon=10^{-4} \quad, \quad \alpha_{1}^{(0)}=5 \quad \mathrm{~W} /\left(\mathrm{m}^{2} \cdot \mathrm{K}\right)$, $\Delta \alpha_{1}=0.5 \mathrm{~W} /\left(\mathrm{m}^{2} \cdot \mathrm{K}\right), \Delta t=5 \mathrm{~min}$.

Computational domain (Fig. 2) is covered with the FEM mesh which consists of 709 triangles. Using the above algorithm, the fifth iteration gives us $\lambda_{2}=0.027 \mathrm{~W} /(\mathrm{m} \cdot \mathrm{K}), \alpha_{1}=6.5 \mathrm{~W} /\left(\mathrm{m}^{2} \cdot \mathrm{K}\right)$.

Relative error of $\lambda_{2}$ and $\alpha_{1}$ is not more than $3 \%$ for the method used.

The standard deviation $T\left(M^{*}, t\right)$ of $T_{*}\left(M^{*}, t\right)$ with the found values $\lambda_{2}$ and $\alpha_{1}$ on the interval $[0,30 \mathrm{~min}]$ was $1.3{ }^{\circ} \mathrm{C}$ (Fig. 3), which is acceptable. The same deviation is in the point $N^{*}$.

The developed mathematical model and the algorithm allowed defining temperature distribution in the solenoid in the steady-state condition (Fig. 4), which was reached within $12 \mathrm{~h}$, as well as dependences $T\left(M^{*}, t\right)$, $T\left(N^{*}, t\right)$ (Fig. 5) and the steady-state temperatures $T_{\mathrm{st}}\left(M^{*}\right)=173.4^{\circ} \mathrm{C}, T_{\mathrm{st}}\left(N^{*}\right)=80.9^{\circ} \mathrm{C}$.

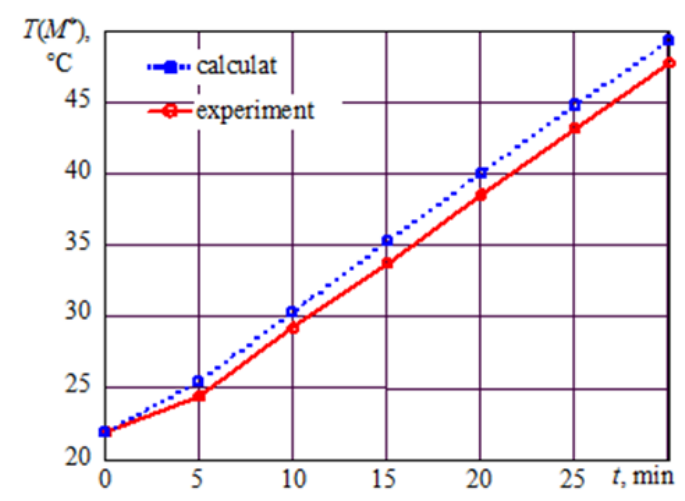

Figure 4. Results of measurements and temperature calculation in the point $M^{*}$ 


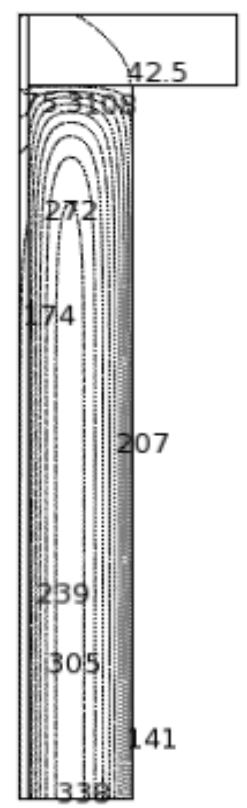

Figure 5. Temperature distribution in the solenoid cross-section in the steady-state condition

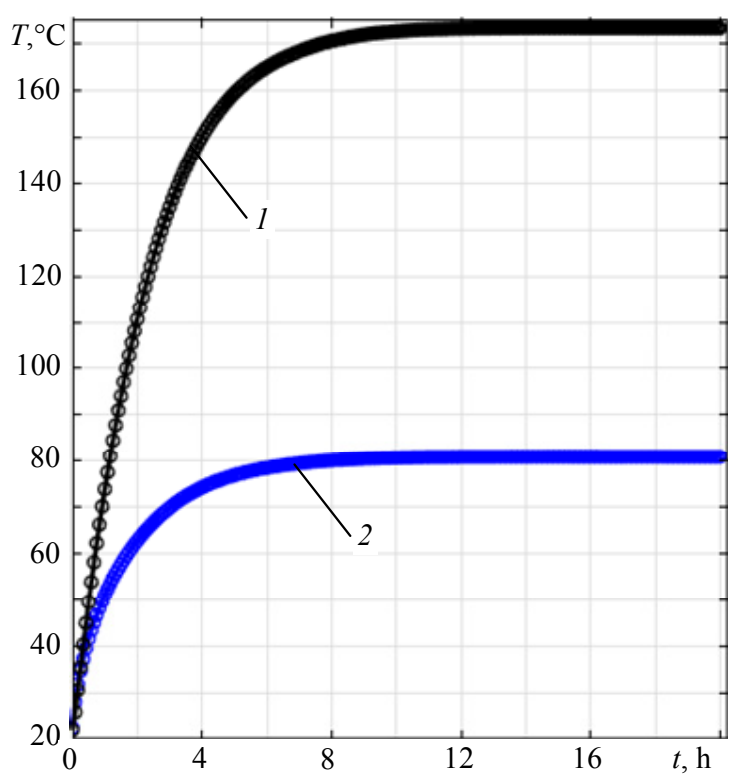

Figure 6. Temperature-time curve in the points $M^{*}$ and $N^{*}: 1-T\left(M^{*}, t\right) ; 2-T\left(N^{*}, t\right)$

Let us check if the first law of thermodynamics is satisfied in the reached steady-state (temperature $T_{\mathrm{st}}$ ) - the capacity supplied to the solenoid winding shall be equal to the sum of heat energy radiated from the solenoid surface to the ambient environment:

$$
\left.U I=\alpha_{1} S_{\text {int }}\left|T_{\mathrm{st}}\left(M^{*}\right)-T_{\mathrm{amb}}\right|+\alpha_{2} S_{\mathrm{ext}} \mid T_{\mathrm{st}}\left(N^{*}\right)-T_{\mathrm{amb}}\right\rfloor,
$$

Where $\quad S_{\text {int }}=\pi \cdot 2 r_{1} L=3.14 \cdot 24 \cdot 10^{-3} \cdot 505 \cdot 10^{-3}=0.0384 \quad \mathrm{~m}^{3}, \quad S_{\text {ext }}=\pi \cdot 2 r_{3} L=3.14 \cdot 0.1 \cdot 505 \cdot 10^{-3}=0.1586$ $\mathrm{m}^{3}$.

Based on (11) we have:

$18.75 \cdot 7.53=6.5 \cdot 0.0381 \cdot(173.4-22)+11.1 \cdot 0.1586 \cdot(80.9-22)$ or $141.2 \approx 141.17$.

Consequently, heat transfer and heat emission coefficients of the test unit and temperature distribution in it can 
be evaluated with an adequate accuracy based on the solution of the inverse heat transfer problems.

\subsection{Thermophysical parameters of an Electromagnetic Valve Actuator of an ICE Gas Distribution Mechanism}

Quick-action electromagnetic actuators are used as basic parts in many fuel delivery and air/gas mixing assemblies of ICEs. They are used for gas distribution mechanisms with individual valve actuators, blow off valves, gas recirculation systems and other devices, which improve energy, economic and environmental performance indicators of motors (Bolshenko, (2013), (Dresner and Barkan, (1989). The actuators work under conditions of excessive power loads, which makes it necessary to study heat parameters of the equipment operation.

A mathematic model represented by a system of equations (10) with boundary conditions on the outside surface of the actuator (2) is used to analyze heat transfer processes in the valve actuator of the ICE gas distribution mechanism (Figure 7).

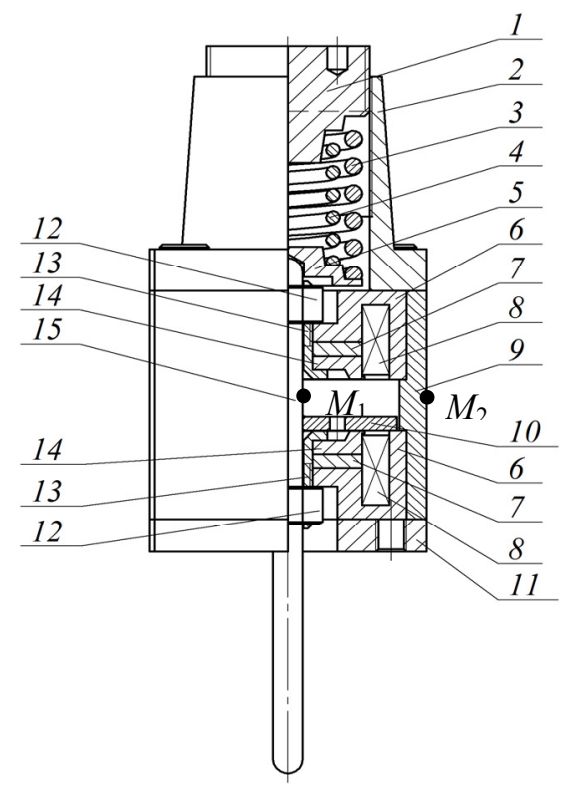

Figure 7. Electromagnetic valve actuator of a gas distribution mechanism

1 -adjusting screw; 2 - upper flange; 3 - external valve spring; 4 - internal valve spring; 5 - stop; 6 - solenoid mounting plate; 7 - constant magnet; 8 - coil; 9 - housing; 10 - anchor; 11 - lower flange; 12 - nut; 13 - bush; $14-$ hub; $15-\operatorname{rod}$

Unknown parameters in our case are equivalent coefficients of heat transfer $\lambda_{e q}$, specific heat capacity $c_{e q}$ and equivalent density $\rho_{e q}$ of the coils 8 , as well as a heat emission coefficient $\alpha$ of the housing 9. Other parameters are known.

To solve an inverse heat transfer problem on a trial actuator and the time interval $\left[0, t_{e}\right]$ functions $T_{*}\left(M_{1}, t\right)$ in the point $M_{1}$ with the relative error $\delta\left(T_{*}\left(M_{1}\right)\right)$ and heat flux density $q_{*}\left(M_{2}, t\right)$ in the $M_{2}$ with the relative error $\delta\left(q_{*}\left(M_{2}\right)\right)$ are measured (Figure 7).

The inverse problem shall be solved using the following algorithm. We shall select initial values $\lambda_{e q}^{(0)}, c_{e q}^{(0)}$, $\rho_{e q}^{(0)}$. Then, we solve the system (10), (12) and find the function to be minimized:

$$
J^{(n)}=\sum_{j=1}^{p} \beta_{1}\left(\frac{T_{j}^{(n)}\left(M_{1}\right)-T_{j^{*}}\left(M_{1}\right)}{T_{j *}\left(M_{1}\right)}\right)^{2}+\beta_{2}\left(\frac{q_{j}^{(n)}\left(M_{2}\right)-q_{j *}\left(M_{2}\right)}{q_{j *}\left(M_{2}\right)}\right)^{2},
$$


where $\beta_{1}, \quad \beta_{2}-$ weight factors, $\beta_{1}=1 / 3 ; \quad \beta_{2}=2 / 3 ; \quad T_{j}^{(n)}\left(M_{1}\right)=T^{(n)}\left(M_{1}, t_{j}\right) ; \quad q_{j}^{(n)}\left(M_{2}\right)=q^{(n)}\left(M_{2}, t_{j}\right) ;$ $T_{j^{*}}\left(M_{1}\right)=T_{*}\left(M_{1}, t_{j}\right) ; \quad q_{j^{*}}\left(M_{2}\right)=q_{*}\left(M_{2}, t_{j}\right) ; t_{j}-$ point of time on the interval $\left[0, t_{\mathrm{i}}\right]: p-$ number of $j^{\text {th }}$ points on the interval $\left[0, t_{e}\right]$.

Then, we shall check the condition

$$
J^{(n)} \leq \delta_{\max }^{2}
$$

where $\delta_{\max }=\max \left[\delta\left(T_{*}\left(M_{1}\right)\right), \delta\left(q_{*}\left(M_{2}\right)\right)\right]$.

If the condition (13) is satisfied, the problem is solved. If not, then new values of the desired variables shall be found using a gradient method of minimizing the function (12), and we shall go to the start of the algorithm.

Let us consider using the described algorithm to solve an inverse heat transfer problem for the given actuator, (Figure 8): $D_{\mathrm{ext}}=56 \mathrm{~mm} ; h_{\mathrm{em}}=49 \mathrm{~mm} ; h=65 \mathrm{~mm} ; H=108.5 \mathrm{~mm}$.

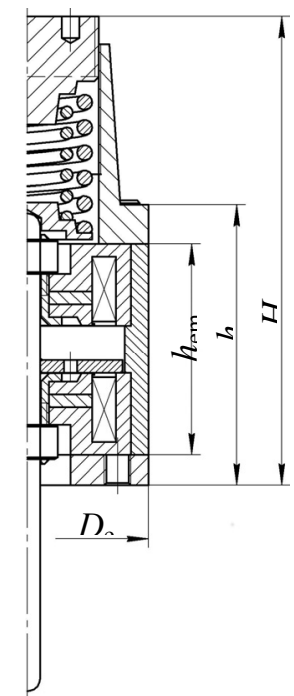

Figure 8. Main dimensions of the actuator

Design of the actuator, its dimensions, properties of the accessories ( $\rho, c, \lambda$-density, specific heat capacity, heat transfer coefficient), except for the same parameters of the coils 8 , relative errors of the temperature measurement $\delta\left(T_{*}\left(M_{1}\right)\right)$ and the heat flux density $\delta\left(q_{*}\left(M_{2}\right)\right)$ are known.

The actuator parts: $1-6,10-12,14,15$ are made from steel (grade 1010); 7 - NdFe35; 8 - copper; 9 aluminum; 13 - brass .

Testo 922 is used to measure temperature, relative error of the temperature measurement $\delta\left(T_{*}\left(M_{1}\right)\right)=1 \%$, ITP-MG4.03/3(1) Potok is used to measure heat flux density, relative error $\delta\left(q_{*}\left(M_{2}\right)\right)=6 \%$.

As the result of the solution of the inverse heat transfer problem the following parameters are defined: $\lambda_{e q}=0.03 \mathrm{~W} /(\mathrm{m} \cdot \mathrm{K}) ; \quad c_{e q}=164 \mathrm{~J} /(\mathrm{kg} \cdot \mathrm{K}) ; \rho_{e q}=6800 \mathrm{~kg} /\left(\mathrm{m}^{3}\right) ; \alpha=18 \mathrm{~W} /\left(\mathrm{m}^{2} \cdot \mathrm{K}\right)$. Figures 8 and 9 show the functions on the time interval $\left.\mid 0.3 \times 10^{3} \mathrm{~s}\right\rfloor: 1$ - experimental data; 2 - data received from the calculation using 
$\lambda_{e q}, c_{e q}, \rho_{e q}$ and $\alpha$. The standard deviation $T_{*}\left(M_{1}, t\right)$ of experimental data is $2.7 \%$. The standard deviation $q_{*}\left(M_{2}, t\right)$ of experimental data is $5.7 \%$.

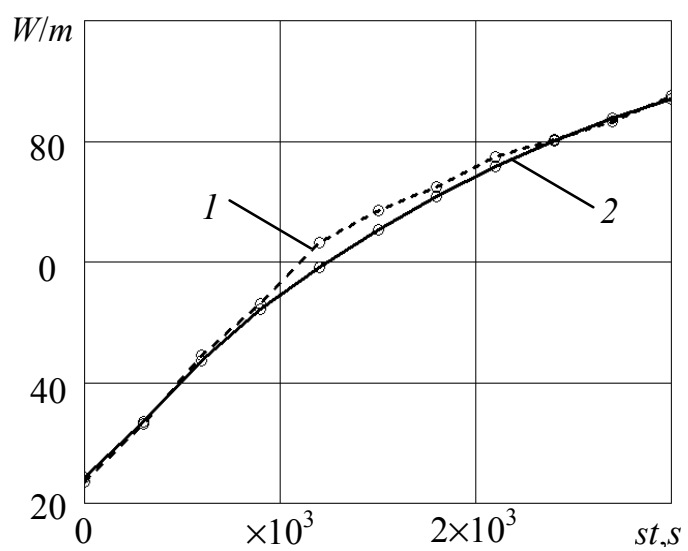

Figure 9. Results of temperature measurement and calculation in the point $M_{1}$

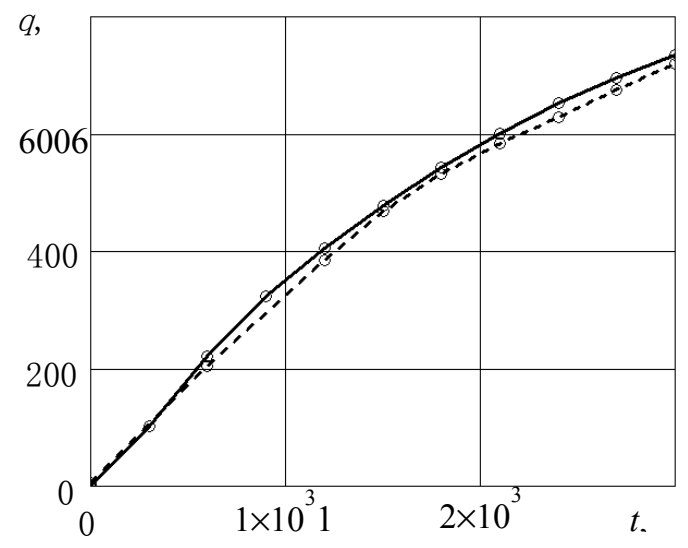

Figure 10. Results of heat flux density measurement and calculation in the point $M_{2}$

The undertaken studies of the heat transfer processes in the actuator using the developed model showed that at the ambient temperature of $150{ }^{\circ} \mathrm{C}$, actuating pulses with the duration of $0.5 \mathrm{~ms}$, the pulse period of $9.5 \mathrm{~ms}$ and the maximum current amplitude of $116 \mathrm{~A}$, the temperature of the actuator winding in the steady-state is $196{ }^{\circ} \mathrm{C}$ and the temperature limit for such insulation class is $200{ }^{\circ} \mathrm{C}$.

\section{Conclusions}

The results of the conducted study show that thermophysical parameters and temperature distribution in non-stationary and steady-state operating conditions of electrical devices may be evaluated with adequate efficiency based on the solution of inverse heat transfer problems.

The developed model and algorithm allow defining maximum temperature of a device as well decreasing time on thermal testing and electric power consumption.

It is planned that further studies will consider internal convection in a heat transfer model, and will help optimize the structure and the operating parameters of electric devices based on the obtained results.

\section{Acknowledgements}

The study results are obtained with the support of the project \#1.2690.2014/K Methods to solve inverse problems of complex system diagnostics (in engineering and healthcare industry) based on full-scale and modeling testing, implemented within the scope of a designing stage for the state-given job. We would like to thank Grichenkova V.P and Bolshenko I.A. for their assistance in conducting the tests. 


\section{References}

Alifanov, O. M. (1994). Inverse Heat Transfer Problems. New York: Springer-Verlag. http://dx.doi.org/10.1007/978-3-642-76436-3

Alifanov, O. M., Artyukhin, E. A., \& Rumyantsev, S. V. (1995). Extreme Methods for Solving Ill-Posed Problems with Applications to Inverse Heat Transfer Problems. New York: Begell House. ISBN:156700038X.

Bachvalov, Y. A., Gorbatenko, N. I., Grechikhin, V. V., \& Grecova, A. N. (2013). Application inverse problems theory magnetic fields in the design of energy-saving electromechanical devices. Izvestiya Vysshikh Uchebnykh Zavedeniy. Elektromekhanika, 5, 28-32. Retrieved from http://electromeh.npi-tu.ru/assets/files/archive_5_2013.pdf

Beck, J. V., Blackwell, B., \& Clair, C. R. jr. (1985). Inverse Heat Conduction: Ill-Posed Problems. New York: John Wiley and Sons. ISBN:0471083194. http://dx.doi.org/10.1002/zamm.19870670331

Bolshenko, I. A. (2013). Review and analysis of designs of electromechanical valve actuators for internal combustion engine. Izvestiya vuzov. Severo-Kavkazskii region. Technical Sciences, 6, 66-73. Retrieved from http://technauka.npi-tu.ru/assets/files/2013-6_annotations.pdf

Borukhov, V. T., Zayats, G. M., Tsurko, V. A., Timoshpol'skii, V. I., \& Andrianov, D. N. (2005). Structural properties of dynamic systems and inverse problems of mathematical physics. Journal of Engineering Physics and Thermophysics, 2(78), 201-215. http://dx.doi.org/10.1007/s10891-005-0050-5

Bui, H. D. (1994). Inverse problems in the Mechanic of Materials: An Introduction. CRC Press. ISBN:0849384710.

Dinh, N. H., \& Reinhardt, H. J. (1998). Gradient Methods for Inverse Heat Conduction problems. Inverse Problems in Engineering, 3(6), 177-211. http://dx.doi.org/10.1080/174159798088027675

Dresner, T., \& Barkan, P. (1989). A Review and Classification of Variable Valve Timing Mechanisms. SAE Technical Paper, 890674. http://dx.doi.org/10.4271/890674

Grechikhin, V. V., \& Grecova, A. N. (2011). Definition of parameters of mathematical models of potential fields by the full-scale modeling method. Izvestiya Vysshikh Uchebnykh Zavedeniy. Elektromekhanika, 1, 18-21. Retrieved from http://electromeh.npi-tu.ru/assets/files/archive_1_2011.pdf

Hall, M., Harmon, S., Patel, H., \& Thomas, O. (2009). Obtaining the d.c. properties of soft magnetic materials using an open circuit measurement technique. Pezeglad Elektrotechniczny, 1(85), 28-30. Retrieved from http://yadda.icm.edu.pl/yadda/element/bwmeta1.element.baztech-article-BPOC-0050-0007

IEC Standard 60404 part 4, Methods of measurement of d.c. magnetic properties of iron and steel.

Korovkin, N. V., Chechurin, V. L., \& Hayakawa, M. (2006). Inverse Problems in Electric Circuits and Electromagnetics. Springer. http://dx.doi.org/10.1007/978-0-387-46047-5

Ozisik, M. N., \& Orlande, H. R. B. (2000). Inverse Heat Transfer: Fundamentals and Applications. New York: Taylor and Francis. ISBN:156032838X.

Polyanin, A. D., Zaitsev, V. F., \& Zhurov, A. I. (2005). Methods for the Solution of Nonlinear Equations of Mathematical Physics and Mechanics. Moscow: Fizmatlit. ISBN:5922105396

Rumyantsev, S. V. (1985). Ways of allowing for a priori information in regularizing gradient algorithms. Journal of engineering physics, 6(49), 1418-1421. http://dx.doi.org/10.1007/bf00871290

Samarskii, A. A. (2001). The theory of difference themes. New York - Basel: Marcel Dekker, Inc. http://dx.doi.org/10.1201/9780203908518

Tikhonov, A. N., \& Arsenin, V. Y. (1977). Solution of Ill-Posed Problems. Washington, DC: Winston \& Sons. ISBN:0470991240.

Tikhonov, A. N., Goncharsky, A. V., Stepanov, V. V., \& Yagola, A. G. (1995). Numerical Methods for the Solution of Ill-Posed Problems. Dordrecht: Kluwer Academic Publishers. http://dx.doi.org/10.1007/978-94-015-8480-7

Vatulyan, A. O. (2007). Inverse Problems in Solid Mechanics. Moscow: Fizmatlit. ISBN:5922108352.

Zienkiewicz, O. C., \& Taylor, R. L. (2000). The finite element method (1st ed.). Vol. 1: The Basis. Oxford: Butterworth-Heinemann. ISBN:0340759844. 


\section{Copyrights}

Copyright for this article is retained by the author(s), with first publication rights granted to the journal.

This is an open-access article distributed under the terms and conditions of the Creative Commons Attribution license (http://creativecommons.org/licenses/by/3.0/). 